\title{
PENANGANAN PELAKU TINDAK PIDANA ILLEGAL LOGING DI WILAYAH HUKUM KEPOLISIAN RESOR LABUHANBATU
}

Oleh :

\author{
Gomgom T.P Siregar dan Rudolf Silaban \\ Universitas Darma Agung Medan \\ Email: \\ gomgomsiregar@gmail.com
}

\begin{abstract}
The purpose of this study was to determine and understand the forms of illegal logging in the Labuhan Batu District Police Legal Area, efforts made by Labuhan Batu Resort Police in tackling illegal logging in the Labuhan Batu District Police Legal Area, the constraints faced by the Labuhan Batu Police Region in tackling illegal logging in the Labuhan Batu District Police Legal Area.

In normative legal research, data collection tools used through searching and / or library research in order to obtain secondary data needed include: Primary legal materials, namely binding legal materials, consisting of legislation relating to the subject matter. Secondary legal materials, namely materials that provide an explanation of primary legal materials, in the form of research results from experts, scientific works, scientific books, and so on. Tertiary legal materials, namely materials that provide explanatory instructions for primary and secondary legal materials, include legal dictionaries, Indonesian dictionaries, encyclopedias.

The results showed that the forms of illegal logging in the Labuhan Batu District Police Legal Area namely, such as the destruction of state-owned forests were used to clear land for residents around the area, wood theft which was used for personal gain or certain parties. The implementation of handling illegal logging cases in Labuhan Batu district which is carried out by carrying out illegal eradication of illegal wood that has been carried out routinely has been carried out properly in accordance with the regulations in force in Labuhan Batu area, but the law enforcement officers and agencies related to the implementation of crime countermeasures illegal logging still has the obligation to make optimal efforts to eradicate crimes of wood theft because this crime still occurs in the Labuhan Batu area. Some obstacles that are faced in the context of implementing illegal logging cases must be immediately overcome so that these illegal logging cases can be completely eradicated, so as to reduce the impact caused by this crime. The constraints faced by the Police of Labuhan Batu Resort in tackling illegal logging in the Legal Area of the Labuhan Batu Police Station include: The absence of specific legislation regarding illegal logging makes the definition and scope of this
\end{abstract}


crime vague and unclear. Funding is needed to conduct operations to eradicate illegal logging. Lack of coordination between the parties involved in carrying out operations to eradicate illegal logging in the forest area and its distribution in Labuhan Batu District. The absence of Civil Servant Investigators (PPNS) in the Forest and Plantation Service Office of Labuhan Batu Regency. Lack of facilities needed for handling illegal logging cases.

Keywords: Handling, Crime, Illegal Loging

\begin{abstract}
ABSTRAK
Tujuan Penelitian ini adalah untuk mengetahui dan memahami bentuk-bentuk illegal loging di Wilayah Hukum Kepolisian Resor Labuhan Batu, upaya yang dilakukan Kepolsian Resor Labuhan Batu dalam menanggulangi illegal loging di Wilayah Hukum Kepolisian Resor Labuhan Batu, kendala-kendala yang dihadapi Kepolsian Resor Labuhan Batu dalam menanggulang illegal loging di Wilayah Hukum Kepolisian Resor Labuhan Batu.

Dalam penelitian hukum normatif, alat pengumpulan data yang dipergunakan melalui penelusuran dan atau studi kepustakaan agar memperoleh data sekunder yang diperlukan antara lain: Bahan hukum primer, yaitu bahan-bahan hukum yang mengikat, terdiri dari peraturan perundang-undangan yang berkaitan dengan pokok permasalahan. Bahan hukum sekunder, yaitu bahan yang memberikan penjelasan mengenai bahan hukum primer, berupa hasil penelitian para ahli, hasil-hasil karya ilmiah, buku-buku ilmiah, dan sebagainya. Bahan hukum tertier, yaitu bahan-bahan yang memberi petunjuk penjelasan terhadap bahan hukum primer dan sekunder, antara lain kamus hukum, kamus bahasa Indonesia, ensiklopedi.
\end{abstract}

Hasil penelitian menunjukkan bahwa bentuk-bentuk illegal loging di Wilayah Hukum Kepolisian Resor Labuhan Batu yaitu seperti, Perusakan hutan milik negara dipergunakan untuk membuka lahan bagi warga sekitar daerah tersebut, Pencurian kayu yang dipergunakan untuk keuntungan pribadi atau pihak-pihak tertentu. Pelaksanaan penaggulangan kasus illegal logging di kabupaten Labuhan Batu yang dilakukan dengan mengadakan operasi pemberantasan kayu secara illegal yang dilakukan dengan rutin sudah terlaksana dengan baik sesuai dengan peraturan yang berlaku di wilayah Labuhan Batu, namun para aparat penegak hukum dan instansi yang terkait dengan pelaksanaan penaggulangan tindak kejahatan pencurian kayu (illegal logging) masih mempunyai kewajiban untuk melakukan upaya secara optimal dalam memberantas tindak kejahatan pencurian kayu karena kejahatan ini masih banyak terjadi di wilayah Labuhan Batu. Beberapa hambatan yang dihadapi dalam rangka pelaksanaan penaggulangan kasus illegal logging harus segera diatasi agar kasus illegal logging ini dapat diberantas secara menyeluruh, sehingga dapat mengurangi dampak yang terjadi akibat tindak kejahatan ini. Kendala-kendala yang 
dihadapi Kepolsian Resor Labuhan Batu dalam menanggulangi illegal loging di Wilayah Hukum Kepolisian Resor Labuhan Batu yaitu antara lain: Tidak adanya peraturan perundang-undangan khusus mengenai tindak pidana illegal logging menjadikan pengertian dan ruang lingkup tindak pidana ini samar dan tidak jelas. Perlu adanya pendanaan untuk mengadakan operasi pemberantasan tindak pidana pencurian kayu (illegal logging). Kurangnya koordinasi diantara para pihak yang terkait dengan pelaksanaan operasi pemberantasan penebangan kayu secara ilegal di kawasan hutan dan peredarannya di Kabupaten Labuhan Batu. Tidak adanya Penyidik Pegawai Negeri Sipil (PPNS) di Dinas Kehutanan dan Perkebunan Kabupaten Labuhan Batu. Kurangnya sarana yang dibutuhkan guna pelaksanaan penaggulangan kasus illegal logging.

Kata Kunci: Penanganan, Tindak Pidana, Illegal Loging

\section{PENDAHULUAN}

Dalam memanfaatkan hutan yang merupakan sumber daya alam yang dapat diperbaharui, diperlukan sistem pengelolaan hutan yang bijaksana. Salah satunya ialah dengan menerapkan prinsip kelestarian. Untuk mencapai tujuan tersebut, maka pemahaman tentang hutan sebagai suatu masyarakat tumbuhtumbuhan serta dipahami oleh semua insan yang memanfaatkan hutan demi kehidupannya melalui penguasaan ilmu dan seni serta teknologi hutan dan kehutanan.

Hutan mempunyai peranan penting bagi kehidupan manusia. Sejak manusia lahir sampai nanti masuk ke liang kubur, manusia memerlukan produk yang dihasilkan dari hutan. Hutan memberikan perlindungan, naungan dan produk-produk yang dibutuhkan manusia untuk kelangsungan hidupnya. Demikian pula hutan merupakan tempat hidupnya binatang liar dan sumber plasma nutfah yang semuanya juga berguna bagi kelangsungan kehidupan manusia di jagad raya ini. Manusia memperoleh produk seperti makanan, obat-obatan, kayu untuk bangunan dan kayu bakar dan juga menikmati manfaat adanya pengaruh dari hutan yaitu iklim mikro serta mencegah erosi dan memelihara kesuburan tanah. Sebagai contoh, misalnya dari kulit pohon Willow, orang Yunani pada zaman dahulu memanfaatkannya dengan cara dikunyah-kunyah sebagai obat pencegah rasa sakit, dan sekarang pun ekstrak kulit pohon Willow merupakan bahan dasar untuk Aspirin. Buah pohon oak merupakan makanan pokok orang Indian di samping jagung. Masyarakat nelayan di Indonesia menggunakan kulit pohon bakau untuk mengawetkan jala. Masyarakat desa di sekitar hutan jati di Jawa memanfaatkan ulat jati sebagai sumber protein hewani. Sementara pada waktu ini tidak kurang 10000 produk yang dihasilkan dari kayu. 
Pada hakekatnya, hutan merupakan perwujudan dari lima unsur pokok yang terdiri dari bumi, air, alam hayati, udara dan sinar matahari. Kelima unsur pokok inilah yang dinamakan panca daya. Oleh karena itu memanfaatkan hutan sebenarnya mengarahkan Panca Daya ini kepada suatu bentuk tertentu pada tempat dan waktu yang diperlukan untuk kesejahteraan dan kebahagiaan manusia lahir dan batin sebesar mungkin tanpa mengabaikan aspek kelestarian.

Hutan disebut suatu areal di atas permukaan bumi yang ditumbuhi pohon-pohon agak rapat dan tumbuhan lainnya serta binatangbinatang yang hidup dalam areal tersebut memiliki hubungan antara satu dengan lainnya, dan membentuk persekutuan hidup alam hayati dan lingkungannya. Secara ringkas batasan hutan ialah komunitas tumbuh-tumbuhan dan binatang yang terutama terdiri dari pohon-pohon dan vegetasi berkayu lainnya yang tumbuh dan berdekatan satu dengan yang lain:

Pasal 1 angka 2 Undang-Undang Republik Indonesia Nomor 41 Tahun 1999 tentang Kehutanan yang selanjutnya disebut UU Kehutanan menentukan bahwa, yang dimaksud hutan adalah "Suatu ekosistem berupa hamparan lahan berisi sumber daya alam hayati yang didominasi pepohonan dalam persekutuan alam lingkungannya, yang satu dengan lainnya tidak dapat dipisahkan".
Undang-undang Kehutanan mengamanahkan dalam konsideran buti 1 bahwa "hutan wajib disyukuri, diurus, dimanfaatkan secara optimal serta dijaga kelestariannya untuk sebesar-besarnya kemakmuran rakyat, bagi generasi sekarang maupun mendatang”. Dengan demikian, fungsi-fungsi hutan tersebut pada hakikatnya merupakan modal alam (natural capital) yang harus ditransformasikan menjadi modal nyata (real capital) bangsa Indonesia yang bertujuan, antara lain yaitu: melestarikan lingkungan hidup, meningkatkan nilai tambah pendapatan, mendorong ekspor non migas dan gas bumi, menyediakan lapangan pekerjaan dan mendorong pembangunan sektor-sektor usaha non kehutanan. Dalam pengelolaan suatu kekayaan termsuk kekayaan hutan harus diatur dengan baik agar tidak terjadi tindak pidana baik itu penyalahgunaan wewenang maupun tentang salah dalam pengaturannya Silen F \& Siregr S (20200, Gurning L, Manurung $M$ \& Simatupang $H$ (2020).

Selain itu dalam Undang-undang Kehutanan bahwa fungsi pokok hutan terdiri dari fungsi lindung dan fungsi produksi yang perlu dijaga keberlangsungannya untuk sebesarbesar kemakmuran rakyat yang berkeadilan dan berkelanjutan. Oleh karena itu pengawasan terhadap hutan sangat penting melihat dari fungsi tersebut.

Surat Keputusan Menteri Kehutanan Nomor: 420/Kpts-II/1991 tentang Perubahan Fungsi Hutan Malino di 
Kecamatan Tinggi Moncong

Kabupaten Gowa Provinsi Dati II

Sulawesi Selatan seluas +3.500

Hektare dari Hutan Produksi menjadi Taman Wisata Alam yang selanjutnya disebut sebagai Kawasan Hutan Taman Wisata Alam Malino Kecamatan Tinggi Moncong Kabupaten Gowa.

Kasus Illegal Logging yang terjadi dikawasan Hutan Taman Wisata Alam Malino Kecamatan Tinggi Moncong Kabupaten Gowa tidak terlepas dari luas daerah kawasan hutan tersebut. Kurangnya jumlah petugas polisi hutan dan tingkat pengetahuan masyarakat yang masih rendah tentang pengelolaan kawasan hutan mengakibatkan kasus Illegal Logging kian marak dan tidak terkontrol. Sehingga dapat mengkibatkan kerusakan hutan secara permanen.

Menurut Forest Watch Indonesia (FWI) Simpul Papua, deforestasi di Indonesia semakin tidak terkendali. Hal ini diakibatkan oleh sistem politik dan ekonomi yang korup, yang menganggap sumber daya alam, khususnya hutan sebagai sumber pendapatan yang bisa dieksploitasi untuk kepentingan politik dan keuntungan pribadi. Hal ini diperkuat dengan fakta-fakta sebagai berikut:

1. Lebih dari setengah kawasan hutan di Indonesia dialokasikan untuk produksi kayu berdasarkan sistem tebang pilih. Banyak perusahaan HPH yang melanggar pola-pola tradisional hak kepemilikan dan hak penggunaan lahan. Menurut klasifikasi pemerintah, saat ini hampir 30\% dari konsesi HPH yang telah disurvey masuk kategori sudah terdegradasi.

2. Hutan tanaman industri telah dipromosikan secara besarbesaran dan diberi subsidi sebagai suatu cara untuk menyediakan kayu bagi industri pulp yang berkembang pesat di Indonesia. Hampir 9 juta ha lahan sebagian besar adalah hutan alam telah dialokasikan untuk hutan tanaman industri.

3. Lonjakan pembangunan perkebunan terutama perkebunan kelapa sawit yakni 7 juta ha lahan hutan telah dirubah untuk perkebunan.

4. Pencurian kayu (illegal logging) turut memperburuk kondisi hutan dengan hampir $\quad 50-70 \%$ kebutuhan kayu untuk segala macam keperluan didapatkan melalui illegal logging dan telah menghancurkan 10 juta ha lahan hutan.

5. Pada era 1985-1997 terjadi pembukaan lahan baru sekitar 4 juta ha hutan untuk dicetak sebagai sawah baru tanpa mempertimbangkan keberlanjutan lingkungan.

6. Program transmigrasi sejak era 1960-1999 telah membuka lahan hutan sebagai tempat pemukiman para transmigran sebesar 2 juta ha lahan hutan.

7. Pembakaran hutan secara sengaja oleh pengusaha HPH dan petani tradisional telah menghabiskan lebih dari 5 juta ha hutan pada 
tahun 1994 dan sekitar 4,6 juta ha lahan hutan pada tahun 19971998.

Kondisi tersebut di atas telah menjadikan hutan kita mengalami deforestasi dan degradasi hutan secara besar-besaran pada hampir 40 tahun terakhir. Kondisi ini diperparah dengan tiadanya usaha untuk menghijaukan kembali hutan yang telah dibabat habis dan ditinggalkan oleh pengusaha HPH maupun oleh petani tradisional akibat berkurangnya potensi lahan secara ekonomis.

Undang-undang kehutanan tahun 1967 memberikan dasar hukum pemberian hak memanen kayu dan banyak HPH besar diberi hak untuk mengelola hutan selama 20 tahun tidak lama setelah Undang-undang tersebut keluar. Undang-undang inilah yang memberi peluang kepada pengusaha kehutanan untuk mengelola hutan secara serampangan dan memulai terjadinya deforestasi dan degradasi hutan di Indonesia yang demikian massive dan tidak terbendung lagi. Pada tahun 1995, ada sekitar 585 konsesi HPH yang luasnya mencakup 63 juta ha diseluruh Indonesia atau kira-kira sepertiga dari luas lahan hutan di Indonesia (Brown, 1993 dalam FWI Simpul Papua). Namun demikian, pada pertengahan tahun 1990-an beberapa izin HPH dicabut, sebagian karena pelanggaran hukum yang dilakukan oleh pemegang konsesi $\mathrm{HPH}$ dan sebagian karena nilai tegakan pohon dibanyak konsesi HPH menurun yang mengurangi daya tariknya sebagai kegiatan komersil jangka panjang. Keadaan kawasan lindung menurut Critycal Ecosystem Partnership Fund, sering menghadapi masalah manajemen sebagai berikut:

1. Kurangnya kemauan politik.

Meskipun deklarasi-deklarasi di tingkat nasional telah mengarah pada penghentian pengrusakan hutan yang illegal dan perdagangan satwa liar, hanya ada sedikit kemauan politik atau perhatian yang terorganisir baik untuk melakukan hal yang sama pada tingkat lokal/pemerintah daerah.

2. Kemiskinan.

Tingkat kesejahteraan para petugas dilapangan memberi andil dalam merebaknya tingkat pengrusakan hutan akibat pemberian izin yang tidak jelas.

3. Korupsi, kolusi dan nepotisme.

Penyalahgunaan wewenang untuk mendapatkan keuntungan pribadi dari para pihak yang terlibat secara langsung dan tidak langsung dalam pengelolaan hutan baik HPH maupun HTI.

4. Penegakan hukum yang tidak berfungsi.

Tiadanya penegakan hukum, khususnya dalam sektor kehutanan bahkan dalam pernyataan-pernyataan resmi Menteri Kehutanan.

5. Dorongan kuat terhadap pembabatan dan perubahan fungsi hutan.

Keuntungan dari industri minyak kelapa sawit dan kebangkrutan industri kertas dan bubur kertas, 
mendorong terjadinya pembabatan, pembakaran dan perubahan fungsi hutan dalam skala besar. Sementara proses pembalakan dan perubahan fungsi hutan itu memberikan manfaat bagi masyarakat lokal yang meskipun tidak sah namun sangat dibutuhkan.

6. Dorongan untuk upaya konservasi tidak memadai.

Nilai dari layanan-layanan ekologis (misalnya pengendalian banjir, fungsi-fungsi aliran air dan pemanfaatan hasil-hasil hutan yang diatur dengan baik) tidaklah difahami dengan baik, sementara hukuman terhadap pembabatan yang illegal kurang memadai.

Beberapa faktor pendorong kerusakan hutan antara lain adalah sebagai berikut:

1. Krisis ekonomi;

2. Perubahan tatanan politik;

3. Lemahnya koordinasi antar aparat penegak hukum;

4. Adanya korupsi, kolusi dan nepotisme;

5. Lemahnya system pengamanan hutan dan pengamanan hasil hutan;

6. Harga kayu hasil tebangan liar yang lebih murah.

Departemen Kehutanan pada tanggal 15 Januari 2003 mengeluarkan informasi (berupa siaran pers) yang menggambarkan kondisi aktual kerusakan hutan tropis serta praktek illegal logging di Indonesia yaitu:
1. Hutan yang rusak dan tidak dapat berfungsi optimal telah mencapai luasan 43 juta hektar dari total hutan Indonesia seluas 120,35 juta hektar dengan laju degradasi 4 tahun terakhir mencapai 2,1 juta hektar pertahun;

2. Penebangan kayu liar dan peredaran kayu illegal mencapai 50,7 juta meter kubik/tahun, dengan perkiraan kerugian financial sebesar $\mathrm{Rp} \quad 30,42$ trilyun/tahun. Di samping itu ada kerugian secara ekologi yaitu hilangnya beberapa jenis/spesies keanekaragaman hayati;

3. Penyelundupan kayu dari Papua, Kalimantan Timur, Kalimantan Barat, Kalimantan Tengah, Sulawesi Tenggara, Riau, Nanggroe Aceh Darussalam, Sumatera Utara, Jambi dengan tujuan negara Malaysia, Cina, Vietnam, India mencapai 10 juta meter kubik/tahun. Khusus dari Papua mencapai 600.000 meter kubik/bulan dengan kerugian sebesar Rp. $\quad 600.000$ Milyar/bulan atau Rp. 7,2 trilyun/tahun;

4. Kerusakan terbesar terjadi di perbatasan Indonesia-Malaysia. Di daerah perbatasan dengan Provinsi Kalimantan Timur laju kerusakan seluas 150.000 hektar/tahun dan di perbatasan dengan Provinsi Kalimantan Barat seluas 250.000 hektar/tahun;

5. Dari hasil kerjasama Dephut dengan TNI AL melalui Operasi Wanabahari pada tahun 2001 telah ditangkap 8 kapal, dengan 
barang bukti sitaan kayu log sebanyak 26.564 meter kubik dengan perkiraan penerimaan negara yang diperoleh sebesar Rp. 63,6 Milyar. Tahun 2002 ditangkap lima kapal dengan barang bukti sitaan berupa kayu olahan 2.500 meter kubik, kayu $\log 11.300$ meter kubik perkiraan penerimaan negara sebesar Rp. 447 Milyar.

\section{METODE PENELITIAN}

Penelitian ini merupakan penelitian yuridis normatif yang bersifat deskriptif analitis, yaitu penelitian yang bertujuan memberikan gambaran tentang: bentuk-bentuk illegal loging di Wilayah Hukum Kepolisian Resor Labuhan Batu, upaya yang dilakukan Kepolsian Resor Labuhan Batu dalam menanggulang illegal loging di Wilayah Hukum Kepolisian Resor Labuhan Batu, kendala-kendala yang dihadapi Kepolsian Resor Labuhan Batu dalam menanggulang illegal loging di Wilayah Hukum Kepolisian Resor Labuhan Batu.

Adapun metode pengumpulan data dalam penelitian ini ditempuh dengan cara Studi Kepustakaan. Menggunakan metode studi kepustakaan diperoleh asas-asas, konsepsi-konsepsi, pandanganpandangan, doktrin-doktrin hukum serta isi kaidah hukum yang diperoleh dari dua referensi utama yaitu yang bersifat umum (perundang-undangan, peraturan, buku-buku teks, kamus) dan yang bersifat khusus (jurnal, laporan penelitian, dan lain-lain).
Dalam penelitian hukum normatif, alat pengumpulan data yang dipergunakan melalui penelusuran dan atau studi kepustakaan agar memperoleh data sekunder yang diperlukan antara lain:

1. Bahan hukum primer, yaitu bahan-bahan hukum yang mengikat, terdiri dari peraturan perundang-undangan yang berkaitan dengan pokok permasalahan.

2. Bahan hukum sekunder, yaitu bahan yang memberikan penjelasan mengenai bahan hukum primer, berupa hasil penelitian para ahli, hasil-hasil karya ilmiah, buku-buku ilmiah, dan sebagainya.

3. Bahan hukum tertier, yaitu bahan-bahan yang memberi petunjuk penjelasan terhadap bahan hukum primer dan sekunder, antara lain kamus hukum, kamus bahasa Indonesia, ensiklopedi dan lain sebagainya.

Analisis data dilakukan secara kualitatif deskriptif, normatif, logis, sistematis, dengan menggunakan metode deduktif dan induktif. Deskriptif artinya data yang diperoleh dari lapangan digambarkan dalam bentuk tulisan sesuai dengan kenyataan yang sebenarnya. Normatif artinya dasar yang dipakai untuk menganalisis data ialah peraturan perundang-undangan yang berlaku di Indonesia, khususnya yang berhubungan dengan permasalahan yang dibahas. Logis artinya bahwa dalam melakukan analisis tidak bertentangan dengan akal sehat dan 
ilmu pengetahuan. Metode deduktif artinya peraturan perundangundangan di Indonesia yang berhubungan dengan permasalahan yang bersifat umum dijadikan sebagai pegangan untuk diterapkan pada data yang diperoleh dari penelitian untuk memperoleh atau menarik suatu kesimpulan. Metode Induktif artinya data yang bersifat khusus yang diperoleh dari penelitian ditarik kesimpulan yang bersifat umum.

\section{HASIL DAN PEMBAHASAN}

\section{Bentuk-Bentuk Illegal Loging Di Wilayah Hukum Kepolisian Resor Labuhan Batu}

Kata hutan merupakan terjemahan dari kata bos (Belanda) dan forrest (Inggris). Forrest merupakan dataran rendah yang bergelombang, dan dapat dikembangkan untuk kepentingan di luar kehutanan, seperti pariwisata. Di dalam hukum tertentu Inggris kuno, forrest (hutan) berarti suatu daerah tertentu yang tanahnya ditumbuhi pepohonan, tempat hidup binatang buas dan burung-burung hutan.

Menurut Dengler yang diartikan dengan hutan adalah:

Sejumlah pepohonan yang tumbuh pada lapangan yang cukup luas, sehingga suhu, kelembaban, cahaya, angin, dan sebagainya tidak lagi menentukan lingkungannya, akan tetapi dipengaruhi oleh tumbuhantumbuhan/ pepohonan baru asalkann tumbuh pada tempat yang cukup luas dan rapat (horizontal dan vertikal).
Ada 4 unsur yang terkandung dari defenisi hutan di atas, yaitu:

a. Unsur lapangan yang cukup luas (minimal seperempat hektare).

b. Unsur pohon (kayu, bambu, palem), flora dan fauna,

c. Unsur lingkungan, dan

d. Unsur penetapan pemerintah.

Unsur pertama, kedua dan ketiga membentuk persekutuan hidup yang tidak dapat dipisahkan satu dengan yang lainnya. Pengertian hutan di sini menganut konsepsi hukum secara vertikal karena antara lapangan (tanah), pohon, flora, dan fauna beserta lingkungannya merupakan suatu kesatuan yang utuh.

Di dalam Pasal 47 Undang-undang Republik Indonesia Nomor 41 Tahun 1999 tentang Kehutanan ditentukan bahwa perlindungan kawasan hutan merupakan usaha untuk:

a. Mencegah dan membatasi kerusakan hutan, kawasan hutan, dan hasil hutan yang disebabkan oleh perbuatan manusia, ternak, kebakaran, daya-daya alam, hama, serta penyakit dan,

b. Mempertahankan dan menjaga hak-hak negara, masyarakat, dan perorangan atas hutan, kawasan hutan, hasil hutan, investasi serta perangkat yang berhubungan dengan pengelolaan hutan.

Di dalam Pasal 46 Undang-undang Republik Indonesia Nomor 41 Tahun 1999 tentang Kehutanan ditentukan, bahwa, "Tujuan perlindungan hutan, 
kawasan hutan dan lingkungannya agar fungsi lindung, fungsi konservasi, dan fungsi produksi tercapai."

Hukum kehutanan merupakan salah satu bidang hukum yang berumur 137 tahun, yaitu sejak di undangkannya Reglemen Hutan 1865. Istilah hukum kehutanan merupakan salah satu bidang hukum Bozwezen Recht (Belanda) atau Forrest Law (Inggris) Black menatakan bahwa:

Yang disebut Forrest Law (Hukum Kehutanan) adalah:

"The system of body of old law relating to the royal forrest". Artinya suatu sistem atau tatanan hukum lama yang berhubungan dan mengatur hutan-hutan kerajaan.

Idris Sarong Al Mar menyatakan bahwa yang dimaksud dengan hukum kehutanan adalah, "serangkaian kaidah atau norma (tidak tertulis) dan peraturan-peraturan tertulis yang hidup dan dipertahankan dalam halhal dan kehutanan".

Hukum kehutanan tertulis adalah kumpulan kaidah hukum yang dibuat oleh lembaga berwenang untuk mengatur hal-hal yang berkaitan dengan hutan dan kehutanan. Hukum kehutanan tidak tertulis atau disebut juga hukum adat mengenai hutan adalah aturan-aturan hukum yang tidak tertulis. Timbul, tumbuh, dan berkembang dalam masyarakat setempat. Jadi hal-hal yang diatur dalam hukum kehutanan tidak tertulis adalah:

a. Hak membuka tanah di hutan; b. Hak untuk menebang kayu;

c. Hak untuk memungut hasil hutan;

d. Hak untuk menggembalakan ternak, dan sebagainya.

Di berbagai daerah, hak-hak tersebut diatur oleh desa, dan dahului, hak- hak adat itu dikuasai oleh negara. Penggunaan hak-hak itu diatur sedemikian rupa, dan tidak boleh bertentangan dengan kepentingan bangsa dan negara. Apabila negara menghedaki penguasaannya, hak- hak rakyat atas hutan tersebut harus mengalah demi kepentingan yang lebih besar. Penguasaan negara ini semata-mata untuk mengatur dan merencanakan peruntukan hutan guna meningkatkan kesejahteraan rakyat.

\section{Upaya Yang Dilakukan Kepolisian Resor Labuhan Batu Dalam Menanggulangi Illegal Loging}

Hukum kehutanan merupakan salah satu bidang hukum yang sudah berumur 137 tahun, yaitu sejak diundangkannya Reglemen Hutan 1865. namun, perhatian ilmuwan hukum terhadap bidang ini sangat kurang. Terbukti kurangnya literatur yang mengkaji hukum kehutanan, sehingga dalam mengidentifikasi rumusan hukum kehutanan masih kurang, penulis mencoba memaparkan pengertian hukum kehutanan dari berbagai pendapat yang ada. 
Dari definisi di atas, tampaklah bahwa hukum kehutanan kuno hanya mengatur hutan-hutan yang dikuasai kerajaan, sedangkan hutan rakyat (hutan milik) tidak mendapat pengaturan secara khusus dalam peraturan perundang- undangan Inggris. Namun, dalam perkembangannya aturan hukum mengenai kehutanan disempurnakan pada tahun 1971 melalui Act 1971. di dalam Act 1971 ini bukan hanya mengatur hutan kerajaan sematamata, tetapi juga mengatur hutan rakyat (hutan milik).

Dalam kaitan dengan ini Idris Sarong Al Mar, mengatakan bahwa yang disebut dengan hukum kehutanan, adalah "Serangkaian kaidahkaidah/norma (tidak tertulis) dan peraturan-paeraturan (tertulis) yang hidup dan dipertahankan dalam halhal hutan dan kehutanan". Hukum kehutanan dalam kedua definisi di atas dititikberatkan pada kekuasaan negara dalam pengelolaan dan pengurusan hutan dan kehutanan semata-mata, padahal persoalan itu tidak hanya menjadi urusan negara, tetapi juga menjadi urusan manusia secara perorangan, jika ia mengusahakan penanaman kayu di atas tanah hak miliknya. Oleh karena itu, penulis cenderung memberikan definisi hukum kehutanan sebagai berikut. Hukum Kehutanan adalah kumpulan kaidah/ketentuan hukum yang mengatur hubungan antara negara dengan hutan dan kehutanan dan hubungan antara individu (perorangan) dengan hutan dan kehutanan.
Ada tiga unsur yang tercantum dalam rumusan hukum kehutanan yaitu : (1) adanya kaidah hukum kehutanan, baik yang tertulis maupun tidak tertulis, (2) mengatur hubungan antara negara dengan hutan dan kehutanan, dan (3) mengatur hubungan antara individu (perorangan) dengan hutan dan kehutanan. Hukum kehutanan tertulis adalah kumpulan kaidah hukum yang dibuat oleh lembaga yang berwenang untuk mengatur hal-hal yang berkaitan dengan hutan dan kehutanan. Hukum kehutanan tertulis ini dapat dilihat dalam peraturan perundang-undangan, baik yang telah dikeluarkan oleh Pemerintah Hindia Belanda maupun yang ditetapkan oleh Pemerintah dengan persetujuan DPR sejak bangsa Indonesia merdeka. Misalnya, Undang-Undang Nomor 5 tahun 1967 tentang Ketentuan-ketentuan Pokok Kehutanan, Undang-undang ini hanya berisi ketentuan yang bersifat pokok saja, sedangkan hal-hal yang lebih rinci diatur dan dituangkan dalam peraturan yang lebih rendah.

Hukum kehutanan tidak tertulis atau disebut juga hukum adat mengenai hutan adalah aturan-aturan hukum yang tidak tertulis, timbul, tumbuh, dan berkembang dalam masyarakat setempat, jadi sifatnya lokal. Hal-hal yang diatur dalam hukum kehutanan tidak tertulis, adalah:

a. hak membuka tanah di hutan;

b. hak untuk menebang kayu;

c. hak untuk memungut hasil hutan;

d. hak untuk menggembalakan ternak, dan sebagainya. 


\section{Kendala-Kendala Yang Dihadapi Kepolisian Resor Labuhan Batu Dalam Menanggulangi Illegal Loging}

Berdasarkan temuan peneliti pihak yang terlibat dalam upaya penegakan tindak pidana illegal loging di daerah Labuhan Batu ada beberapa instansi yang menjadi penegak kasus illegal loging yaitu dari pihak KEPOLISIAN, Dinas Kehutanan, Perum Perhutani, Dari masingmasing instansi ini memiliki kewenangan dan tugas dalam menangani illegal loging yang berbeda, tetapi walaupun berbeda bebrapa instansi ini juga selalu berkordinasi satu dengan yang lain dan melakukan tindakan bersamasama dalam menangani kasus illegal loging di daerah Labuhan Batu.

a. Wewenang dan tugas dari Dinas Kehutanan

Bahwasannya tugas dari Dinas Kehutanan khususnya Dinas Kehutanan Kabupaten Labuhan Batu sudah memenuhi aturan dan tata cara pengelolahan hutan sesuai dengan aturan yang ada. Dinas Kehutanan juga yang berwenang mengeluarkan Surat Keterangan Sahnya Hasil Hutan (SKSHH) tetapi dalam kenyataannya di dalam wewenang ini masih banyak terjadi kecurangan- kecurangan yang di lakukan oleh oknum di dalam dinas kehutanan.

Tugas dan wewenang Perum Perhutani
Perhutani memiliki tugas dan wewenang untuk menyelengrakan perencanaan, pengurusan pengusahaan dan melindungi hutan di wilayah kerjanya. Perum Perhutani juga mengusahakan pelayanan bagi kemanfaatan umum dan sekaligus memupuk keuntungan berdasarkan prinsip pengelolahan perusahaan. Dengan demikian pihak Perhutani memiliki peran yang sangat penting dalam menjaga kelestarian hutan dan dalam menanggulangi tindak pidana illegal loging.

b. Wewenang aparat Kepolisian dalam tindak Pidana illegal loging

Pihak aparat polisi disini bertugas dan memiliki wewenang dalam penyelidikan, penahanan, penangkapan dan penyitaan barang bukti jika ditemukan atau jika tertangkap tangan oleh pihak kepolisian. Pihak kepolisian ini pun ikut serta dalam upaya meminimalisir tindak pidana illegal loging. Dengan cara berkoordinasi dengan pihak terkait dan melakukan operasi gabungan yang di lakukan setiap bulan.

c. Dalam penegakan kasus illegal loging pihak kepolisian kabupaten Lumajang sudah menerapkan pasal-pasal atau jerat hukum yang sesuai dengan peraturan dan Undang-undang yang berlaku. Yaitu Undangundang No.41 Tahun 1999 Tentang kehutanan. 


\section{KESIMPULAN}

Berdasarkan uraian diatas dapat ditarik kesimpulan sebagai berikut.

1. Bentuk-bentuk illegal loging di Wilayah Hukum Kepolisian Resor Labuhan Batu yaitu seperti, Perusakan hutan milik negara dipergunakan untuk membuka lahan bagi warga sekitar daerah tersebut, Pencurian kayu yang dipergunakan untuk keuntungan pribadi atau pihak-pihak tertentu.

2. Pelaksanaan penaggulangan kasus illegal logging di kabupaten Labuhan Batu yang dilakukan dengan mengadakan operasi pemberantasan kayu secara illegal yang dilakukan dengan rutin sudah terlaksana dengan baik sesuai dengan peraturan yang berlaku di wilayah Labuhan Batu, namun para aparat penegak hukum dan instansi yang terkait dengan pelaksanaan penaggulangan tindak kejahatan pencurian kayu (illegal logging) masih mempunyai kewajiban untuk melakukan upaya secara optimal dalam memberantas tindak kejahatan pencurian kayu karena kejahatan ini masih banyak terjadi di wilayah Labuhan Batu. Beberapa hambatan yang dihadapi dalam rangka pelaksanaan penaggulangan kasus illegal logging harus segera diatasi agar kasus illegal logging ini dapat diberantas secara menyeluruh, sehingga dapat mengurangi dampak yang terjadi akibat tindak kejahatan ini.

Upaya yang dilakukan Kepolsian Resor Labuhan Batu dalam menanggulang illegal loging di Wilayah Hukum Kepolisian Resor Labuhan Batu adalah sebagai berikut: keanggotaan tim koordinasi dan tim pelaksana pemberantasan penebangan kayu secara ilegal di kawasan hutan dan peredaannya di Kabupaten Labuhan Batu.

b. Mengadakan rapat koordinasi.

c. Melaksanakan operasi pemberantasan penebangan kayu secara ilegal

d. Petugas melakukan pemeriksaan dokumen asal usul kayu;

e. Apabila ada dugaan bahwa kayu yang ditemukan di tempat lokasi terebut ilegal, petugas segera melakukan tindakan hukum dengan membawa kasus tersebut ke Kantor Kepolisian Sragen untuk dilakukan pemeriksaan;

f. Petugas Kepolisian melimpahkan Berkas Acara Pemeriksaan (BAP) kepada Kejaksaan Negeri Labuhan Batu.

g. Petugas kejaksaan membuat surat dakwaan 
untuk proses persidangan di Pengadilan Negeri Labuhan Batu.

3. Kendala-kendala yang dihadapi Kepolsian Resor Labuhan Batu dalam menanggulangi illegal loging di Wilayah Hukum Kepolisian Resor Labuhan Batu yaitu antara lain:

a. Tidak adanya peraturan perundang-undangan

khusus mengenai tindak pidana illegal logging menjadikan pengertian dan ruang lingkup tindak pidana ini samar dan tidak jelas.

b. Perlu adanya pendanaan untuk mengadakan operasi pemberantasan tindak pidana pencurian kayu (illegal logging).

c. Kurangnya koordinasi diantara para pihak yang terkait dengan pelaksanaan operasi pemberantasan penebangan kayu secara ilegal di kawasan hutan dan peredarannya di Kabupaten Labuhan Batu.

d. Tidak adanya Penyidik Pegawai Negeri Sipil (PPNS) di Dinas Kehutanan dan Perkebunan Kabupaten Labuhan Batu.

e. Kurangnya sarana yang dibutuhkan guna pelaksanaan penaggulangan kasus illegal logging.

\section{DAFTAR PUSTAKA}

Wikipedia Bahasa Indonesia. Pembalakan Liar. http://id.wikipedia.org/wiki/ Halaman Utama.

Suarga,Risa, 2005, Pemberantasan Illegal Logging, Optimisme di Tengah Praktek Premanisme Global, Wana Aksara, Tangerang.

Sunaryati Hartono, C.F.G., 1994, Penelitian Hukum Di Indonesia Pada Akhir Abad ke-20, Bandung, Alumni .

Soekanto, Soerjono, Sri Mamudji, 1995, Penelitian Hukum Normatif, Raja Grafindo Persada, Jakarta.

Salim, H. S., 2006, Dasar-Dasar Hukum Kehutanan, Edisi Revisi, Sinar Grafika, Jakarta.

Ngandung I B., 1975, Ketentuan Umum Pengantar Hutan dan Kehutanan Indonesia, Pusat Latihan Kehutanan, Ujung Pandang.

Sarong Al Mar, Idris, 1993, Pengukuhan Hutan dan AspekAspek Hukum (Suatu Analisa Yuridis) Bagian I, Bahan Penataran Teknis-Yuridis Kawasan Hutan 1992/1993.

Silaen, F., \& Siregar, S. (2020). HUBUNGAN KEBIJAKAN KRIMINAL DENGAN KEBIJAKAN HUKUM PIDANA. Jurnal Darma Agung, 28(1), 8 - 16. 
doi:10.46930/ojsuda.v28i1.455

Gurning, L., Manurung, M., \& Simatupang, H. (2020). UPAYA POLISI AIRUD DALAM PENANGGULANGAN

TERJADINYA TINDAK PIDANA ILLEGAL FISHING DI WILAYAH PERAIRAN TANJUNGBALAI. Jurnal Darma Agung, 28(1), 17 - 30.

doi:10.46930/ojsuda.v28i1.456 